\title{
OCCLUSION OF THE ENTIRE INFERIOR VENA CAVA BY HYPERNEPHROMA, WITH THROMBOSIS OF THE HEPATIC VEIN AND ITS BRANCHES *

\author{
VICTOR C. JACOBSON, M.D.,
} AND \\ ERNEST W. GOODPASTURE, M.D. BOSTON
}

Although renal hypernephroma is of relatively frequent occurrence and metastasis by way of the venous system the usual mode of dissemination of the tumor tissue, it is rare to find extensive growth into the inferior vena cava and rarer still to have an intravascular hypernephroma occlude this vessel in its entire length and extend into the right chambers of the heart.

In the present instance we have the unique picture of occlusion of the entire inferior vena cava from a hypernephroma growing along the left renal vein, completely filling the inferior vena cava from the iliac bifurcation to the right auricle, with the tumor mass extending through the tricuspid orifice into the right ventricle. The hepatic veins were thrombosed. There was acute central necrosis of the liver and death in acidosis.

\section{REPORT OF CASE}

History.-The patient, a man aged 63, entered the medical service of the Peter Bent Brigham Hospital, Jan. 22, 1917 (Med. No. 11605), complaining of swelling of the feet, legs and scrotum, shortness of breath, loss of appetite, and "gas on stomach." At that time the following history was obtained: $\mathrm{He}$ had been a druggist for forty years and quit work but two days previous to entrance. His appetite had been fairly good prior to the last six months, bowels were always regular and he had never had jaundice, colic, vomiting or other gastro-intestinal symptoms. Hematuria had never been noticed. His weight had suffered considerably the previous six months. In September, 1916, he weighed 184 pounds and on entrance to the hospital only 113 pounds. $\mathrm{He}$ said the marked loss of weight was due to his poor appetite.

After returning from his vacation in September, 1916, he noticed that his appetite was failing, and soon he began to have eructations of gas after eating. During the last three months he could not eat as much as previously because he felt "filled up" and at times, but not frequently, he regurgitated a little food. He gradually decreased the amount eaten at a meal but did not eliminate any elements of his diet. There was distress and sense of fullness in the epigastrium after meals.

Three weeks before admission he noticed for the first time that his legs and scrotum were slightly swollen, more so at night. A physician told him

* Submitted for publication March 20, 1918.

*From the Medical Clinic and Pathological Laboratory of the Peter Bent Brigham Hospital. 
his urine contained a little albumin and he was warned against "kidney trouble." Digitalis, taken for two weeks, caused no improvement in the swelling. Ten days later another physician prescribed gentian and iron, with the result that his appetite increased. There was then marked shortness of breath on exertion, gradually increasing, but not sufficient to keep him from work. Three days before admission his urine was examined but no albumin was found. $\mathrm{He}$ was advised to enter the hospital to rest up.

Physical Examination.--At entrance this showed the patient well developed and fairly well nourished, complaining of the coldness of the ward. His skin was white and covered with dry, oily scales. His thorax was long, narrow and rather full. The respiratory movements were normal. The cardiac impulse was in the fifth interspace, $13 \mathrm{~cm}$, to the left of the midsternal line, the left border $15 \mathrm{~cm}$. out in the fifth interspace, the right border $3.5 \mathrm{~cm}$. to the right of the midsternal line, the upper border at the third rib. At the apex the sounds were slow and regular, the first sound sharp and preceded by a soft presystolic murmur and followed by a long, blowing diastolic murmur which was transmitted into the axilla. A short systolic murmur was heard in the aortic area, loudest in the second right interspace and not transmitted. The peripheral vessels were tortuous and easily palpated. There was a Corrigan pulse but no Duroziez' sign.

In the lungs were many fine crackling râles along the lower borders. The abdomen was scaphoid and there was shifting dulness in the flanks. There was a sense of resistance in the epigastrium, but no definite mass was felt, nor were there any areas of tenderness. The liver dulness extended from the fifth rib to the costal margin. The spleen and kidneys could not be felt. The penis and scrotum were edematous. The legs showed moderate soft edema.

Clinical Pathology.-Hemoglobin (Sahli), 63 per cent. ; erythrocytes, 3,700,000. Smear showed no abnormal forms. The urine contained a slight trace of albumin and a moderate number of hyaline casts. The phenolsulphonephthalein output was 42 per cent. in two hours. Clinical diagnosis, chronic cardiac valvular disease, aortic insufficiency, syphilitic aortitis (?), secondary anemia, chronic nephritis. He was given digitalis leaves, $0.1 \mathrm{gm}$. four times a day.

The following day a capillary pulse was noted in his finger nails. January 29 , temperature, pulse and respiration were normal. After twelve doses of $0.1 \mathrm{gm}$. digitalis leaves, diuresis occurred with a loss of $6.4 \mathrm{~kg}$. The blood Wassermann reaction was double plus. Gastric analysis showed anacidity. The edema of the extremities was much decreased but had not entirely disappeared.

February 6. Roentgen report: "Negative gastro-intestinal findings. In the gallbladder region there is a suggestive shadow, but not sufficient to be due to a calculus."

February 12. The urine contained the slightest possible trace of albumin but no erythrocytes or casts. He had lost 12 pounds in weight and complained of "weakness of stomach." He would have liked to eat more but could not. His speech was rambling.

February 14. Edema was more marked in the right leg than in the left. The glands in the right groin were enlarged and tender. The right saphenous vein for one third the distance to the knee was very tender. Apparently thrombosis of the saphenous vein could account for the unilateral edema.

February 20. Blood pressure: systolic 150, diastolic 80 .

February 23. The abdominal veins were enlarged, the blood flowing from below upward. There was marked edema of the right leg and slight edema of the left leg. The abdomen was rather full, especially the upper part. No masses were felt. The signs were those of obstructed inferior vena cava.

February 27. Blood pressure: systolic 130, diastolic 80 .

April 2. Blood pressure: systolic 140, diastolic 80 .

April 4. There was a definite fluid wave in the flanks. The liver edge suddenly became palpable $9 \mathrm{~cm}$. below the costal margin in the right mammary 
line. He had a strong "acetone" breath and vomited frequently. The respirations were of the character of acidosis.

He later became comatose. Alveolar air carbon dioxid tension $11.6 \mathrm{~mm}$. $\mathrm{Hg}$; temperature $97 \mathrm{~F}$. He was given 3 per cent. sodium bicarbonate in

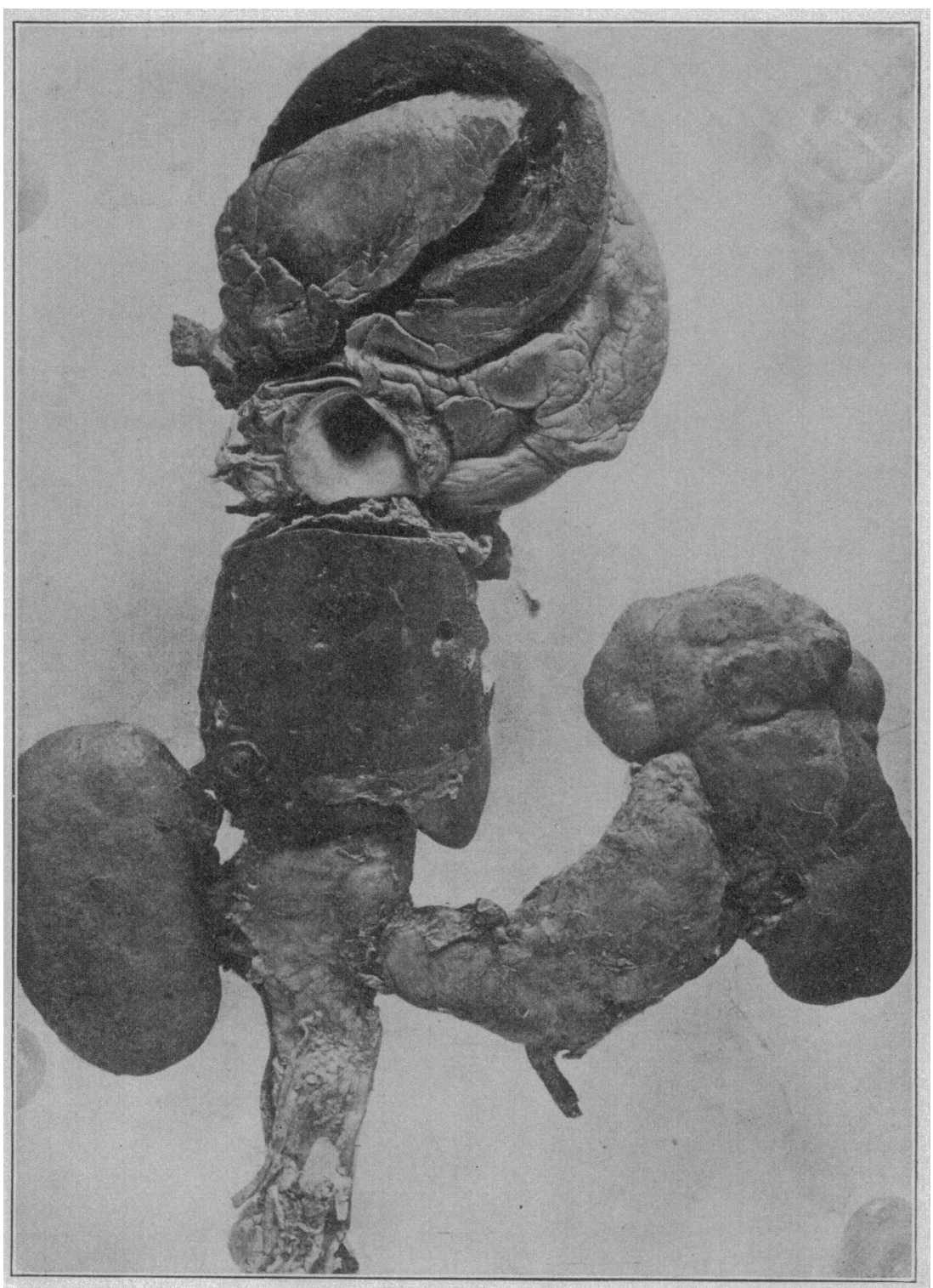

Fig. 1.-Anterior view of authors' specimen.

physiologic sodium chlorid solution per rectum by Murphy drip. Catheter specimen of urine, 500 c.c., showed a moderate amount of diacetic acid. Shortly a fiter $6 \mathrm{p}$. $\mathrm{m}$. his respirations slowed down and stopped.

Necropsy.-Performed sixteen hours postmortem by Dr. E. W. Goodpasture. 
Diagnoses.-Hypernephroma of left kidney with invasion of left renal vein, inferior vena cava and one of right renal veins; occlusion of inferior vena cava; metastases to liver and lungs; multiple diverticuli of duodenum and jejunum; aortic arteriosclerosis; hypertrophy of heart, left; dilatation of aortic ring; congestion of liver; ascites and bilateral hydrothorax; edema; fatty degeneration of heart; bronchopnetumonia.

Body: The body was that of a large framed, middle aged, white man, showing considerable emaciation. The tissues were flabby and there was considerable edema of extremities, the legs pitting easily on pressure. The thorax was barrel shaped, abdomen protuberant.

Peritoneal Cavity: Contained 180 c.c. of clear yellow fluid; liver extended two fingers' breadth below the costal margin in the right mammary line; diaphragm on both sides at fourth interspace.

Thoracic Cavity: Lungs were voluminous, each covered largely by thin, tough, fibrous adhesions; 300 c.c. clear yellow fluid in each pleural cavity.

Heart: Enlarged, especially the left side; mitral ring measured $9 \mathrm{~cm}$., aortic $8.25 \mathrm{~cm}$.; aortic valve was normal except for extensive thickening about the corpora arantii and glueing together and calcification between the posterior and right cusps; myocardium was very flabby and pale yellow; heart was left in situ because of necessity of careful dissection of inferior vena cava which was filled with tumor growth extending into the right auricle.

Lungs: Voluminous; lateral portion of right lung and anterior portion of left lung were covered by fibrous adhesions. On the surface of each lung a great number of yellow, firm tumor nodules up to $2 \mathrm{~cm}$. in diameter, for the most part smaller, were scattered irregularly over the surface. On section similar tumors were found scattered throughout the lung substance. The tumor masses were rather opaque on the cut surface, very soft and grayishyellow in color. Sometimes the centers were soft and yellow, while the peripheries were more translucent. A yellow opaque center was often surrounded by a red zone and the peripheral gray tissue appeared to be vascular.

Gastro-Intestinal Tract: The duodenum was normal for $6 \mathrm{~cm}$. beyond the pylorus. At this point there was a diverticulum lying just over the head of the pancreas, $2.5 \mathrm{~cm}$. in diameter. Just opposite Treitz' ligament was another diverticulum measuring $2.5 \mathrm{~cm}$. in diameter, and $6 \mathrm{~cm}$. below was a very large diverticulum $5 \mathrm{~cm}$. in diameter. All opened into the intestine, as could be determined by squeezing air from them into the intestine. Beyond the largest were a dozen smaller in the fat of the mesenteric attachment for a distance of one foot.

Liver: Larger than normal, dark purple. On section lobulation was distinct, centers purple, depressed, portal areas grayish yellow. The hepatic veins from the largest to the smallest were plugged with dark, purple thrombi. In the middle anterior portion of the left lobe a small mass was found measuring 5 mm., with a grayish pink center and yellowish periphery, which appeared to be a tumor metastasis.

Tumor: A large mass occupying the region of the left kidney on section was found to be a hypernephroma occupying the upper two-thirds of the kidney substance. It measured $10 \mathrm{~cm}$. in length and $8 \mathrm{~cm}$. in width. The surface of the kidney in the region of the tumor was lobulated and the capsule was very vascular. On section through the tumor it presented a yellow, opaque surface composed of tissue resembling adrenal cortex. Numerous small hemorrhages were scattered throughout the tumor and there was a pink tone to the tumor tissue, indicating great vascularity. Brighter yellow opaque areas were scattered through the tumor which appeared to be areas of necrosis.

The right kidney was of normal size. The capsule was smooth, stripped easily, leaving a' slightly irregular surface. The left renal vein was tremendous. It was plugged and distended with soft yellow tumor tissue, and measured $12 \mathrm{~cm}$. in length and $5.5 \mathrm{~cm}$. in diameter. The inferior vena cava was completely plugged with tumor growth both in the upper and lower portions, from 
the origin of this renal vein. In its upper portion, however, it was very greatly dilated, being $5.5 \mathrm{~cm}$. in diameter, the lower portion $3 \mathrm{~cm}$. in diameter, and became attenuated as the pelvis was approached. Both internal iliac veins were plugged with tumor thrombi. The tumor extended upward in the vena cava into the right auricle and ventricle, but the great distention of the vein

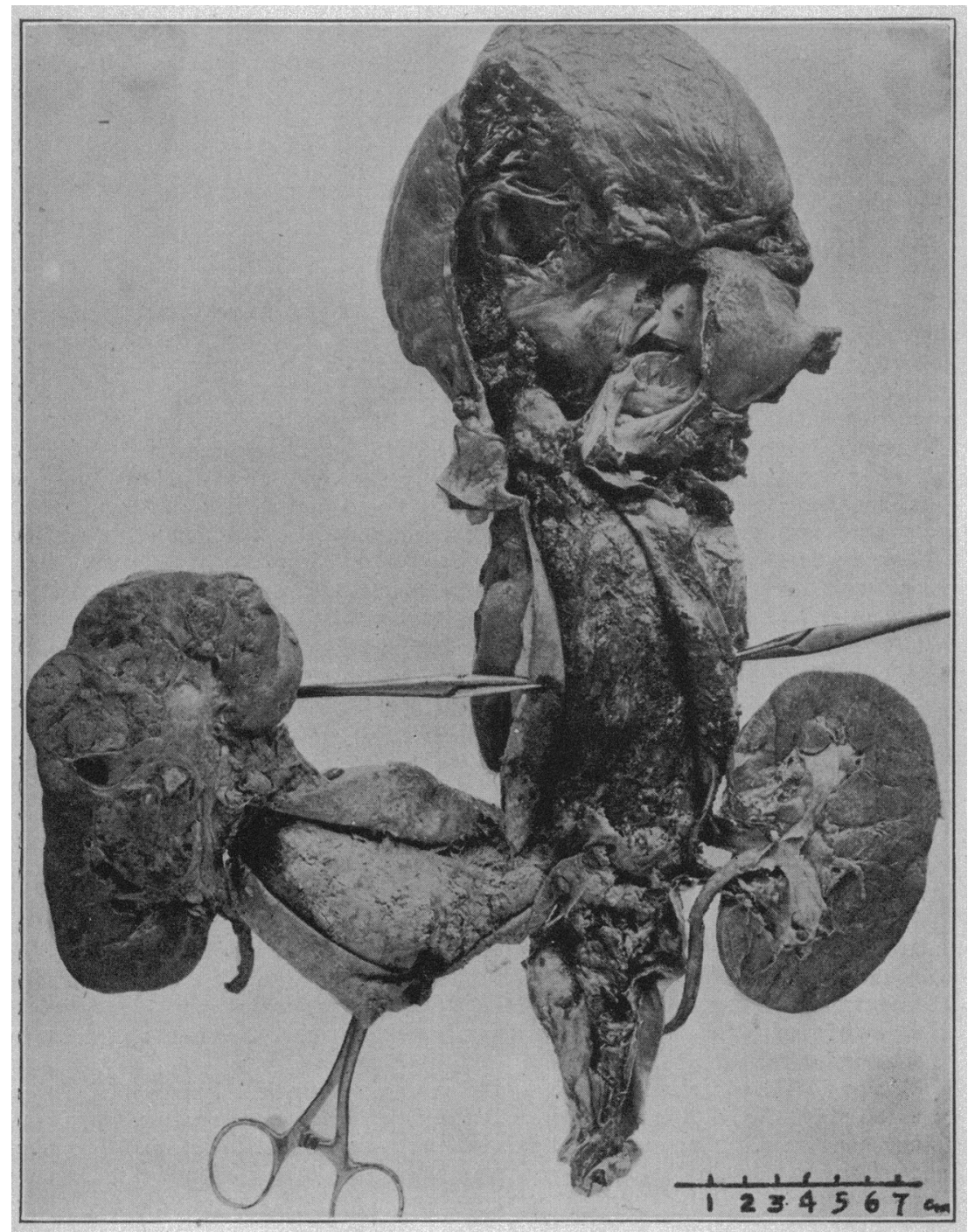

Fig. 2.-Posterior view of specimen.

ended at the diaphragm. Above this point it measured $2.5 \mathrm{~cm}$. in width. The right renal veins were two in number and about normal in size. The superior vein, $1 \mathrm{~cm}$. in diameter, was patent in its entire length. The inferior right vein was $0.5 \mathrm{~cm}$. in width, deep purple and quite solid. The pelvis of each kidney and the ureters were normal. 
Adrenals: Normal in size and normal in general. The left adrenal could be almost completely dissected out from the tumor about its superior surfaces, but inferiorly, next to the kidney, it was invaded by tumor mass and could not be separated from it. The perirenal fat of the left kidney was very thick and firm. On section this fat showed evident tumor extension in the connective tissue between the fat lobules, but the rigidity of the fat did not appear to be due entirely to tumor growth, but probably to connective tissue thickening between the fat lobules. There was some fat of yellow, opaque appearance, rather than translucent.

Pelvic Organs: The vessels about the prostate were thrombosed.

Microscopical Examination.-Left Kidney: The tumor is composed chiefly of polyhedral cells with pale or clear, vacuolated cytoplasm. The nucleus, containing one or two basophilic nucleoli, is centrally or eccentrically placed. The cells are arranged chiefly in alveolar form, but columnar formation is also present. In some sections tubular architecture is strikingly predominant, strongly suggesting renal tubules. There are many large and small vascular spaces lined with a single layer of flat epithelium and containing much blood. There are many small thrombi undergoing hyalinization. The tumor is not sharply marked off from the renal substance proper. The cortex of the kidney shows much fibrosis and hyalinization of glomeruli and obliteration of the normal tubular arrangement. Sections of the tumor from the renal pelvis show a less differentiated type and arrangement of the cells, the latter tending to be more spindle shaped than polyhedral.

Right Kidney: Chronic passive congestion and moderate amount of fatty change in convoluted tubules.

Lung: There are many scattered small nodules of tumor tissue which occupy alveoli, the walls of which are thickened. There is marked chronic passive congestion.

Spleen: Shows chronic passive congestion.

Liver: There are obliterating thrombi in the tributaries of the hepatic veins and extensive central necrosis of the liver substance with hemorrhagic infiltration in the necrotic areas. The normal columnar architecture is retained only at the peripheral portions of some of the lobules. There is very little polymorphonuclear reaction within the areas of necrosis. Sections of the thrombi from the hepatic veins show no tumor tissue, and the thrombi are apparently of recent origin, with the exception of one in the quadrate lobe in which organization has begun.

Bone Marrow: The bone marrow is hyperplastic.

Thrombus: Section of the thrombus from the inferior vena cava and right auricle show almost solid infiltration with tumor cells, with little tendency to any definite arrangement. There is great variation in size, shape and intensity of staining of the individual cells.

The thrombi from the right renal veins contain no tumor tissue.

Sections of the thrombi occluding the caval orifices of the hepatic veins show no tumor tissue. The thrombus in the vein draining the quadrate lobe shows beginning organization; those involving the right and left lobes are apparently about twenty-four hours old.

Portions of the thrombus from $4 \mathrm{~cm}$. below the iliac bifurcation in the right and left common iliac veins contain a few strands of tumor cells, which, however, are more spindle-shaped and not vacuolated, corresponding more to the morphology of the tumor cells in the cardiac thrombus.

In the left renal vein, just proximal to the caval orifice, sections of the tumor mass show a strikingly tubular arrangement of tumor cells, but no basement membrane was demonstrable with Mallory's phosphotungstic acid-hematoxylin stain. 
Pleasants, ${ }^{1}$ in 1911 , was able to collect 314 cases of obstruction of the inferior vena cava. Of this number 171 were due primarily to thrombosis, the majority of which were associated with inflammatory foci elsewhere in the body. Obstruction due to new growths (Geschzeulst-thrombose) occurred 88 times; by invasion, 48 ; by pressure, 21 ; and by thrombosis, 19 . Due to new growths in the kidney, 29 times, classified as follows: carcinoma, 21 times, causing invasion 12 , pressure 2 and thrombosis 6 times. Sarcoma 8 times, causing invasion 5 , pressure 2 and thrombosis 1 time. Due to new growth in the suprarenal gland, 3 times; sarcoma, 3 times, causing invasion 1, pressure 1 , and thrombosis 1 time. Invasion was found to be most frequent in the middle third of the cava and the most common path of invasion was through the renal veins, and in an upward direction. Obstruction by pressure from without arose most frequently also in the middle third, owing to the nearness of the liver and other structures. Thrombosis was commonest in the lower third but also occurred in the upper and middle thirds through disease of the affluent veins.

Of the cases of Geschzoulst-thrombose, in 43 cases accurately described, Pleasants found the lower third alone occluded in 9 cases and lower and middle thirds together in 7 cases; the middle third alone in 6 cases and the middle and upper thirds together in 17 cases. In only one instance was the entire cava from the iliacs to the right auricle filled. In 13 cases the growth reached as far as the right auricle or actually invaded it.

The most striking symptoms or physical signs of obstruction of the vena cava encountered were, lumbar pain, edema of the lower extremities and abdominal wall, and the establishment of collateral circulation. All of these features were found to depend on the position, extent, rapidity and completeness of the obstruction. The most strikingly developed of the superficial collateral circulatory rontes was the superficial inferior epigastric-internal mammary channel. This was the collateral channel shown in our case. In many instances, with no superficial routes evident, the blood reaches the heart through deep vessels, the most frequent way being through the internal iliacascending lumbar-azygos-superior vena cava anastomosis.

There are several extraordinary features in our case: (a) The remarkable extension of the tumor from the upper pole of the left kidney to the left renal vein to the inferior vena cava which it traversed below as far as the iliac bifurcation and grew upward into the right auricle and right ventricle, causing mechanical embarrassment to the tricuspid valve. The nodules in the lungs were most likely derived from emboli from this portion of the tumor. Of the right renal veins

1. Pleasants: Johns Hopkins Hosp. Rep., 1911, 16, 363. 
(there being two), the inferior one was distended with red thrombus extending in from the inferior vena cava as far as the renal pelvis. The orifices of the hepatic veins were plugged with the tumor and metastases were present in the liver substance. $(b)$. The first noticeable symptoms occurred seven and one-half months before death. They were in the nature of loss of appetite, sense of fullness after eating, and gastro-intestinal discomfort of more or less vague character. Edema of the legs and scrotum appeared five months later, during which time there was a loss in weight of 70 pounds. However, the patient was able to attend to his work right up to the time of his entrance to the hospital, where he came merely to get "rested up." $(c)$. The absence of hematuria. (d). The late appearance of definite signs of obstruction of the inferior vena cava in spite of the fact that that vessel was occluded in its entire length at necropsy. (e). The acute swelling and centro-acinous necrosis of the liver from thrombosis of the hepatic veins and death in acidosis. The sudden enlargement of the liver noted clinically was probably associated with the hepatic thrombosis.

Metastases in hypernephroma are frequently extensive. Growth of the tumor along the renal vein to the inferior vena cava from the affected kidney is not so common. Ribbert ${ }^{2}$ in his Geschwulst Lehre mentions a case in which the tumor ascended the inferior vena cava to the right auricle without obstructing the hepatic veins. J. Israel ${ }^{3}$ and Rolleston ${ }^{4}$ have reported instances of invasion of the inferior cava, the latter's case being secondary carcinoma of the right suprarenal, extending in along the capsular vein.

The remarkable patient of Parkes Weber $^{5}$ showed symptoms of obstructed inferior vena cava, enlarged liver and spleen, and ascites. The last two days there occurred anuria, uremia, coma and death. Necropsy disclosed a thrombus-containing tumor (papilliferous adrenal carcinoma) commencing in the left renal vein, involving both renal veins, both hepatic veins, the whole of the inferior cava, with the upper end projecting into a partially occluded right auricle. Both adrenals and kidneys were infiltrated with "malignant hypernephroma." Nodules of tumor were present in the liver and lungs. The liver also showed the central necrotic changes of extreme passive congestion. Death occurred from thrombosis of the better kidney with resultant anuria and uremia.

Herbert French ${ }^{6}$ has described a case of carcinoma of the left kidney with a continuous clot of tumorous tissue extending along the left renal

2. Ribbert: Geschwulste Lehre, 1904, p. 35.

3. Israel: Deutsch. Med. Wchnschr., 1904, 30, 489.

4. Rolleston and Marks: Am. Jour. Med. Sc., 1898, 116, 404.

5. Weber, Parkes: Proc. Royal Soc., 1915, 8, 6.

6. French: Tr. Med. Soc., London, 1912, 35, 243. 
vein, up the inferior vena cava into the right auricle, producing an intracardiac polypoid mass leading to tricuspid stenosis of the ball and socket type. Rolleston ${ }^{\top}$ quotes Adami as having seen a similar extension of adrenal tumor.

Other neoplasms, such as carcinoma and teratoma of the testis, ${ }^{8}$ have produced extensive deposits in the inferior vena cava. Thrombosis may give rise to a similar train of symptoms from occlusion of the inferior cava, hepatic veins and extension into the right auricle.

The symptoms produced by simple occlusion of the hepatic veins are not always very definite. The syndrome of Craven Moore, ${ }^{9}$ progressive enlargement of the liver, signs of involvement of the inferior vena cava and ascites, is mentioned by Osler ${ }^{10}$ as being characteristic of stenosis of the orifices of the hepatic veins. In Chiari's ${ }^{\mathbf{1 1}}$ three cases which had a luetic background, death occurred from ascites and pulmonary edema. Winternitz ${ }^{12}$ ligated an hepatic vein in a dog and observed no untoward effect or any macroscopic or microscopic changes in the liver.

In our case, twenty four hours before death the liver suddenly became greatly enlarged, the patient developed symptoms of acute acidosis with strong "acetone" breath, alveolar air carbondioxid tension of $11.6 \mathrm{~mm}$. $\mathrm{Hg}$, and diacetic acid was found in the urine. The central necrosis of the liver lobules and the thrombi behind the tumor tissue in the orifices of the hepatic veins appeared to be about twenty-four hours old.

The sudden enlargement of the liver coincident with the onset of acidosis suggests a point which may be of diagnostic significance in acute thrombosis of the hepatic veins, where there are already signs of obstruction of the inferior vena cava.

The more rapid cases of hepatic obstruction give a picture which much resembles myocardial failure, there being present cyanosis, congestion of the lungs, enlarged tender liver, and ascites. ${ }^{13}$ The rarity of thrombi in the hepatic ostia has been attributed to the marked obliquity of the veins and also to the diminished coagulability of the hepatic blood. ${ }^{14}$

The structure of the tumor in our case is interesting in that the tubular arrangement of the cells is quite the predominating architecture in some sections and the individual cells are strikingly like those

7. Rolleston: Diseases of Liver and Bile Ducts, 1912, p. 498.

8. McCallım: Textbook of Pathology, 1916, p. 1010.

9. Craven Moore: Med. Chron. Series 4, 1902, 3, 240.

10. Osler: The Principles and Practice of Medicine, 1915, 563.

11. Chiari: Zeigler's Beitr. z. Path. Anat. u. z. Allg. Path., 1899, 2ô, 1.

12. Winternitz: Bull. Johns Hopkins Hosp., 1911, 22, 396.

13. Thompson and Turnbuli, Quart. Jour. Med., 1912, 5, 277.

14. Kretz: Ergebn. d. allg. Path., 1902, 8, 498. 
of normal renal tubules, being cuboidal and with granular cytoplast: instead of being vacuolated. There are all gradations between the cells of the normal kidney tubule and the more primitive, less differentiated, heavily fat-laden cell of typical hypernephroma.

\section{SUM MARY}

Occlusion of the inferior vena cava by new growth (Geschwulstthrombose) is rare, up to 1911 there having been but forty-three cases accurately described. In thirteen of these the growth reached as far as the right auricle or actually invaded it. In only one instance was the entire cava from iliacs to right auricle filled. Since then several other instances of obstruction by intravascular new growth have been reported, two of which showed occlusion from the level of the renal veins with tumor projecting into the right auricle. In one case the tumor tissue completely filled the inferior vena cava and extended into the right auricle.

The case reported here is one in which a renal hypernephroma extended from the kidney into the left renal vein, traversed the inferior vena cava below as far as the iliac bifurcation and grew upward into the right auricle and right ventricle causing mechanical embarrassment to the tricuspid valve.

The orifices of the hepatic veins were plugged with tumor, and there was acute central necrosis of the liver from thrombosis of the hepatic vein and its branches. Sudden enlargement of the liver was accompanied by the onset of acidosis which persisted until the death of the patient twenty-four hours later.

Where there are already signs of obstruction of the inferior vena cava, sudden enlargement of the liver coincident with the onset of acidosis is probably indicative of acute thrombosis of the hepatic veins. 